\title{
A New Mechanism for the Electrostatic Charge Build-up and Dissipation in Dielectrics
}

\author{
Lucas C. Soares, Sérgio Bertazzo, Thiago A. L. Burgo, Victor Baldim and Fernando Galembeck*
}

Instituto de Química, Universidade Estadual de Campinas, CP 6154, 13084-971 Campinas-SP, Brazil

\begin{abstract}
O excesso de cargas induzidas em papel, sob um potencial eletrostático foi determinado utilizando-se o método de Kelvin. Os resultados mostraram que o papel, sob um potencial elétrico positivo, acumula excesso de cargas negativas que são dissipadas quando o potencial elétrico é reduzido à zero. As velocidades de eletrização e re-neutralização do papel mostraram-se fortemente dependentes da umidade atmosférica e são interpretadas de acordo com um novo modelo para a eletrificação de isolantes, que é baseado no efeito do potencial elétrico sobre o potencial eletroquímico $\left(\mu_{\mathrm{i}}=\mu_{\mathrm{i}}^{\circ}+\mathrm{RT} \ln \mathrm{a}+\mathrm{zFV}\right)$ dos íons $\mathrm{H}\left(\mathrm{H}_{2} \mathrm{O}\right)_{\mathrm{n}}{ }^{+} \mathrm{e} \mathrm{OH}\left(\mathrm{H}_{2} \mathrm{O}\right)_{\mathrm{n}}{ }^{-}$existentes na água adsorvida nos isolantes. $\mathrm{O}$ modelo é capaz de explicar os resultados experimentais apresentados neste trabalho, bem como outros fenômenos eletrostáticos.
\end{abstract}

Excess electrostatic charge induction on paper under an electrostatic potential, at different relative humidity $(\mathrm{RH})$ values, was measured using a Kelvin electrostatic voltmeter set-up. Results show that samples under a positive potential accumulate excess negative charges, which are dissipated when the potential is brought down to zero. Rates of charge accumulation and dissipation over the samples are equal under constant $\mathrm{RH}$ and both rates decrease markedly at lower RH values. These results are interpreted using a new model for the electrification of insulators, based on the effect of the electric potential on the electrochemical potential $\left(\mu_{\mathrm{i}}=\mu_{\mathrm{i}}^{\circ}+\mathrm{RT} \ln \mathrm{a}+\mathrm{zFV}\right)$ of $\mathrm{H}\left(\mathrm{H}_{2} \mathrm{O}\right)_{n}{ }^{+}$and $\mathrm{OH}\left(\mathrm{H}_{2} \mathrm{O}\right)_{n}{ }^{-}$ions within water adsorbed on insulators. Rates of paper electrification and re-neutralization are thus strongly dependent on the amount of water in the atmosphere. This model explains the experimental results presented in this work and also a number of hitherto unexplained reports on electrostatic phenomena.

Keywords: electrostatic, insulators, water clusters, potential decay, adsorption

\section{Introduction}

Electrostatic induction phenomena have been studied for centuries and results are consolidated e.g. in Maxwell's Treatise. ${ }^{1}$ Fundamental concepts are well established and their application is straightforward for metals and semiconductors but not for insulators. Insulator electrostatic charging is hardly reproducible or predictable ${ }^{2}$ and this is related to the current lack of agreement on the nature of charge carriers in electrified insulators, as observed by many authors. ${ }^{3-8}$

Current thinking considers that electrification of a dielectric arises from charge displacement within the solid under the action of an external electric field, following arguments presented by Kohlrausch. ${ }^{9}$ A macroscopic electric dipole (or multipole) is thus formed, aligned with the field on which the solid is immersed. Following these

*e-mail: fernagal@iqm.unicamp.br ideas, charge displacement from one solid to another is held as the mechanism for electret formation by contact electrification.

The influence of the surrounding atmosphere on electrostatic phenomena is well-known but it is not well understood. A recent paper by Hogue et al..$^{10}$ describes the influence of atmospheric pressure on insulator-insulator contact charging and it presents an ion transfer mechanism for the charge exchange process. Verdaguer et al. ${ }^{11}$ used scanning probe microscopy to show that water vapor adsorption decreases the electric potential gradients in the vicinity of steps in $\mathrm{NaCl}$ crystals. On the other hand, Folan et al. ${ }^{12}$ did not find an effect of atmospheric water on the charge of a polymer particle contacting nickel. A recent report ${ }^{13}$ describes the effect of water adsorption on polymer contact charging but it is interpreted as a modifying factor in the electron-pair donor-acceptor interactions that these authors hold responsible for contact charging. 
Atmospheric plasma made by trapping corona ions on fine ice particles dispersed in the air has been used to suppress electrostatic discharges while handling thermoplastic pellets. ${ }^{14}$ In a study on air conditioning applications, the effect of pulsed corona plasma on water vapor desorption for a given power was found superior over conventional thermal desorption. ${ }^{15}$ A more indirect evidence on the role or water adsorption on electrostatic charging was given in a study on the performance of microelectromechanical systems (MEMS). ${ }^{16}$

Recent work from this laboratory described a technique for creating reproducible electrostatic patterns on a thinfilm silica surface and the results were interpreted using a simple mechanism based on atmospheric water sorptiondesorption coupled to charge-injection from gold electrodes into the silica film. ${ }^{17}$

These results led to the formulation of the following hypothesis: electrostatic phenomena under atmospheric conditions have a contribution from atmospheric ions as well as from excess ions generated by charging of adsorbed water. Atmospheric ions are charge carriers that migrate under the action of electric fields, distribute within electric potential gradients according to Poisson-Boltzmann equation, adsorb on solid and liquid surfaces, and discharge electrochemically on metal and semiconductor surfaces.

On the other hand, water at equilibrium under an electrostatic potential $\mathrm{V}$ shows excess $\mathrm{H}\left(\mathrm{H}_{2} \mathrm{O}\right)_{n}{ }^{+}$ion concentration if $\mathrm{V}<0$ and excess $\mathrm{OH}\left(\mathrm{H}_{2} \mathrm{O}\right)_{n}{ }^{-}$concentration if $\mathrm{V}>0$, according to the electrochemical potential definition,

$\mu_{\mathrm{i}}=\mu_{\mathrm{i}}^{\circ}+\mathrm{RT} \ln a_{\mathrm{i}}+\mathrm{z}_{\mathrm{i}} \mathrm{FV}$

where, $\mu_{i}$ is the electrochemical potential of species $i, \mu_{i}^{o}$ is the chemical potential of species $i, R$ is the gas constant, $T$ is the temperature, $a_{i}$ is the activity of species $\mathrm{i}, z_{i}$ is the valence of species i, $F$ is the Faraday constant and $V$ is the electric potential.

Electrostatic induction experiments with sheets of paper, varying the humidity and the number of sheets, were conceived to test this hypothesis and are reported in this paper.

\section{Experimental}

Experiments were done with quantitative filter paper sheets (square of $50 \pm 2 \mathrm{~mm}$ of size, $0.021 \pm 0.001 \mathrm{~mm}$ thick), (Nalgon), using the apparatus shown in Figure 1.

This apparatus consists of a closed aluminum box fitted with holders for a Kelvin vibrating electrode, test samples, temperature and relative humidity sensors and

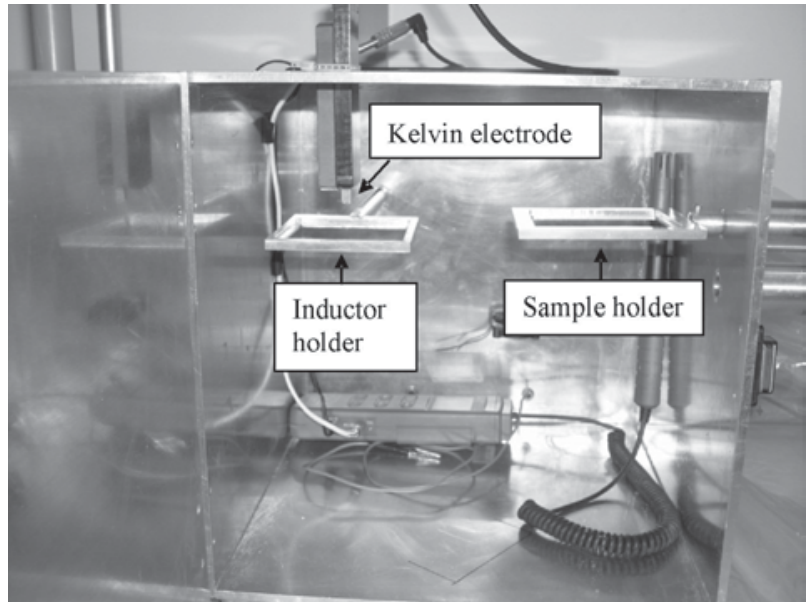

Figure 1. Picture of the apparatus used to hold samples, the electrified insulator and the vibrating electrode. The apparatus door is open.

also for a piece of plastic that was previously electrified and allowed to reach the desired potential, measured by the electrostatic voltmeter. The electrode was fixed, and the test sample as well as the electrified plastic could be introduced beneath the electrode or drawn $15 \mathrm{~cm}$ away, using external handles.

Temperature and humidity within the aluminum box were continuously monitored using a thermo-hygrometer (Minipa model MTH-1380) connected to a data acquisition board (National Instruments multifunctional A/D I/O board AT-MIO-16X model) mounted on a microcomputer. The atmosphere within the box was established by passing a current of humidified nitrogen gas (White Martins). To change the relative humidity $(\mathrm{RH})$ of the gas current, part of it was diverted into a gas washer filled with distilled water. This allowed control of RH within the $0 \%$ to $70 \%$ range, $\pm 2 \%$. Temperature was kept constant at $22 \pm 1{ }^{\circ} \mathrm{C}$ by using the air-conditioning system in the room.

Potential measurements were made using a TRek electrostatic voltmeter model 368A fitted with a TRek electrostatic probe model 3800E-2. The Kelvin probe sensor has a square surface and $25 \mathrm{~mm}^{2}$ area.

The voltmeter was grounded and connected to the ATMIO-16X National board as well as to a Pharmacia strip chart recorder. The potential determined by the electrostatic voltmeter is always in relation to the ground potential.

Software used for handling data was DAQWare v2.1, supplied by National Instruments and Test Link v1.4.2.0 supplied with the hygrometer. Data processing and analysis were done using Origin 6.1.

The electrical field was generated by an acrylic plaque that was electrified by rubbing against a polyethylene sheet. This produces excess positive charges on acrylic. The electrified plastic was kept in its holder until it displayed the desired potential, as measured in the electrostatic voltmeter. 


\section{Induction experiments}

Charge induction experiments were performed as follows: the sheets of paper were placed $2 \mathrm{~mm}$ beneath the probe of the electrostatic voltmeter (following the manufacturer's instructions) and they were left under rest until reaching electrostatic equilibrium with the environment inside the box (at this point the potential registered by the electrostatic voltmeter is constant at a fixed value, usually $0 \pm 2$ volts. After the electrostatic equilibrium is reached, an acrylic sheet (electrified by friction) was placed $(1.9 \pm 0.2) \mathrm{cm}$ beneath the insulator, as shown in Figure 1. The electrified plastic is named "inductor", in this text. The electrostatic voltmeter output was then continuously recorded, while the following operations were done: first, the inductor was cyclically introduced beneath the electrode and removed, to verify its stability (control step). Then, while the inductor was withdrawn, the sample was placed beneath the electrode and the inductor was again cyclically introduced and removed. Finally, the sample was withdrawn and the inductor was again introduced and removed, to check for its potential stability.

\section{Effect of the dielectric constant of paper upon the electric potential}

The effect of the dielectric constant of paper upon the electric potential generated by the inductor can be estimated when the experimental set-up (Kelvin electrode, paper sheet and inductor) is considered as a parallel-plate capacitor, whose plates are $2 \mathrm{~cm}$ apart in air, with a paper sheet inserted between the layers. The electric potential between these two plates can be determined by equation $2 .{ }^{18}$

$$
V=V_{0}\left(\frac{d_{1}}{d_{T} K_{1}}+\frac{d_{2}}{d_{T} K_{2}}\right)
$$

where $V$ is the potential between plates while the compound (paper + air) is in between them, $V_{0}$ is the potential in vacuo, $d_{1}$ is the thickness of the paper sheet $(0.02 \mathrm{~mm}), d_{2}$ is the interplate distance minus the thickness of the paper sheet $(1.98 \mathrm{~cm}), d_{T}$ is the distance between the plates of the capacitor, $K_{1}$ is dielectric constant of the paper sheet $(3.5)^{19}$ and $K_{2}$ is the dielectric constant of air.

\section{Calculation of charge density}

The electric potential of the charges built-up in the paper sheet can be rigorously obtained by using equation 3 , provided that we consider that the paper sheet is a cylinder.
By using polar coordinates and considering the center of the cylinder as the origin, it is possible to determine the electric potential generated at a given distance by a uniform distribution of charges in that cylinder. ${ }^{18}$

$V=\frac{\rho}{4 \pi \varepsilon} \int_{0}^{2 \pi} \int_{0}^{Z} \int_{0}^{R} \frac{r}{\sqrt{\left((s+d)^{2}+r^{2}\right)}} d r d s d \phi$

where $V$ is the electric potential generated by the cylinder, $\rho$ is the charge density, $\varepsilon$ is the dielectric constant of the medium, $Z$ is the thickness of the cylinder, $R$ is the total radius of the cylinder, $r$ is any radius inside the cylinder, $d$ is the distance from the surface of the cylinder to the detector, $s$ is the distance from any point inside the cylinder to the detector and $\phi$ is the angle that scans the base area of the cylinder.

However, since the experiments were done using square sheets of paper, for the sake of easier sample handling and to have data for geometry relevant for practical applications, the figures obtained using equation 3 can only be used as estimates of the actual charge density. The incurred deviations were estimated by calculation of charge densities in a cylinder inscribed in the sheet and also a cylinder tangent to the sheet vertices. The charge densities given in Results are the averages between those for the internal and external cylinders.

\section{Results}

The results are presented as the potential measured by the Kelvin probe $v s$. time, for different numbers of sheets of paper and distinct RH values. A large number of replicates showed the reproducibility of measurements as well as the strong dependence of the measured potentials on the humidity of the nitrogen atmosphere. A typical potential vs. time plot (at $10 \% \mathrm{RH}$ and with one sheet of paper), recorded while the inductor is periodically introduced beneath the electrode and then withdrawn, together with the representation of the position of the inductor, probe and paper, is shown in Figure 2.

In Figure 2, voltmeter readings change from $c a .0$ to above $800 \mathrm{~V}$ and vice-versa, when the inductor is introduced beneath the electrode and then removed. The potential changes are fast, as evidenced by the nearly vertical lines separating the readings made when the inductor is inserted or withdrawn. There is a small overshoot in the potentials read following the introduction or removal of the charged inductor that is due to vibration caused by the handle displacement.

Readings taken while the paper sheet is in between the inductor and the electrode are quite different: first, 


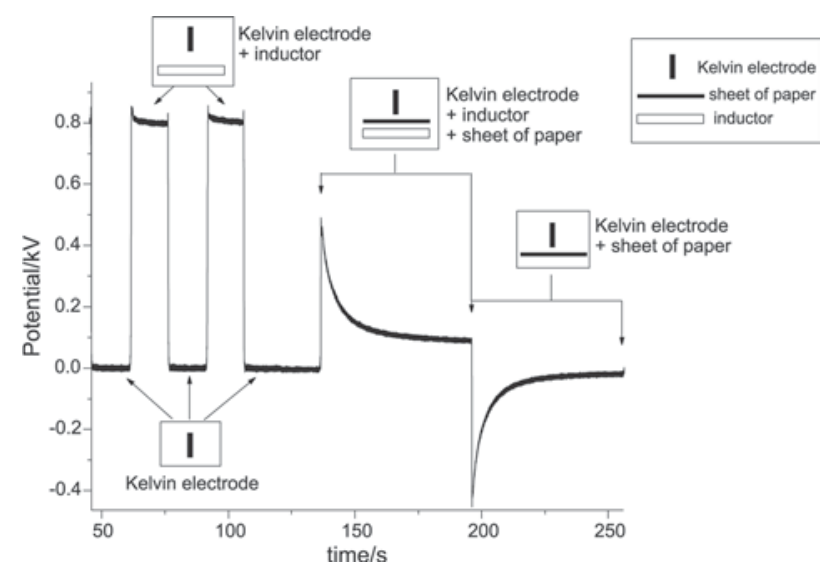

Figure 2. Potential $v s$. time (at 10\% RH and with one sheet of paper). The inductor was periodically introduced beneath the electrode during the experiment. The quasi-square waves to the left were recorded when the inductor was introduced and removed while the paper sample was withdrawn, and the spikes in the central part show potential readings when the paper sample is positioned beneath the electrode. Positive potentials were all observed when the inductor was introduced and near-zero or negative potentials were obtained while the inductor was withdrawn.

the paper sheet shields the inductor effectively but not instantly, since the potentials measured by the electrode are always much lower than $900 \mathrm{~V}$ and they decrease fast, approaching $0 \mathrm{~V}$ at high humidity. On the other hand, when the inductor is removed, the potentials read by the electrode are negative but they increase quickly to zero. There is a remarkable symmetry between the potential curves recorded while the inductor is inserted or withdrawn. Moreover, the experiment can be repeated over and over again resulting on reproducible plots without any signs of irreversible changes. These two observations can be understood assuming that the electric charge build-up and dissipation steps of the experiment are opposite steps of the same reversible process and further, that this is independent of the charging state of the sample.

Figure 3 shows readings taken under $10-70 \%$ relative nitrogen atmosphere humidity. The effect of the humidity on the sample charging pattern is clearly seen and it can be represented by the following parameters: $i$ ) maximum and minimum potentials read when the inductor is introduced or removed; $i$ ) decay rate constants $(\mathrm{k})$ of the potential vs. time curves, that were fitted empirically as $\mathrm{V}=\mathrm{Vo}+\left[\mathrm{A} * \mathrm{e}^{(-\mathrm{kt})}\right]$ equation. These are summed up in Table 1.

Table 1 and Figure 3 show interesting features: the potential $v s$. time curves are symmetric and the decay rate constants vary significantly with RH values, with a 5-fold increase from 10 to $40 \% \mathrm{RH}$.

Figure 4 shows readings taken under $10 \%$ relative nitrogen atmosphere humidity, varying the number of sheets of paper. The effect of the number of sheets on the charging pattern is readily seen and is very similar to the effect of atmosphere humidity variation. Increasing the relative humidity as well as increasing the number of paper sheets, the electrode is effectively shielded from the acrylic sheet. Since the increase in relative humidity and the increase in the quantity of sheets of paper have a analogous effect on the potential measurements, it is possible to conclude that the factor that determines charging is the mass of water adsorbed on paper.

Measurements were also obtained at $0 \pm 1 \% \mathrm{RH}$, as presented in Figure 5. Potential changes very slowly when the inductor is introduced beneath the sample and also when it is withdrawn. Under these conditions, the base line is not reached even after 10 minutes.

Figure 5 shows that shielding at $0 \%$ RH is considerably less than observed in the measurements at higher humidity, and it increases only slightly over time, at comparatively much lower rates. This slight variation of the electric potential can be due to traces of water sorbed in the paper or even to water released by condensation reactions.

Because this reduced shielding observed at $0 \% \mathrm{RH}$ may be partly due to stray capacitance associated to the geometry of the sample holder, the empty sample holder (without the paper sheet) was inserted between the Kelvin electrode and the inductor under various RH. The results

Table 1. Results extracted from Figure 3: maximum and minimum potentials following inductor insertion or withdrawal, potential ratios and decay constants

\begin{tabular}{|c|c|c|c|c|c|c|}
\hline RH (\%) & $\begin{array}{c}\mathrm{A}=\text { Maximum potential } \\
\text { following insertion of } \\
\text { inductor }(\mathrm{V})\end{array}$ & $\begin{array}{c}\mathrm{B}=\text { Minimum potential } \\
\text { following inductor } \\
\text { withdrawal }(\mathrm{V})\end{array}$ & $\begin{array}{c}\mathrm{C}=\text { Electrode reading } \\
\text { when the sample is } \\
\text { withdrawn }(\mathrm{V})\end{array}$ & $\mathrm{A} / \mathrm{C}$ & $\mathrm{B} / \mathrm{C}$ & $\begin{array}{l}\text { Decay constant } \\
\text { (k) after inductor } \\
\text { insertion }\left(\mathrm{s}^{-1}\right)\end{array}$ \\
\hline 70 & 26 & -31 & 962 & 0.027 & -0.032 & --- \\
\hline 60 & 46 & -56 & 860 & 0.053 & -0.065 & --- \\
\hline 50 & 45 & -52 & 859 & 0.052 & -0.060 & --- \\
\hline 40 & 89 & -77 & 856 & 0.104 & -0.089 & 0.66 \\
\hline 30 & 179 & -174 & 854 & 0.209 & -0.203 & 0.31 \\
\hline 20 & 299 & -332 & 849 & 0.352 & -0.391 & 0.24 \\
\hline 10 & 490 & -456 & 852 & 0.575 & -0.535 & 0.12 \\
\hline
\end{tabular}



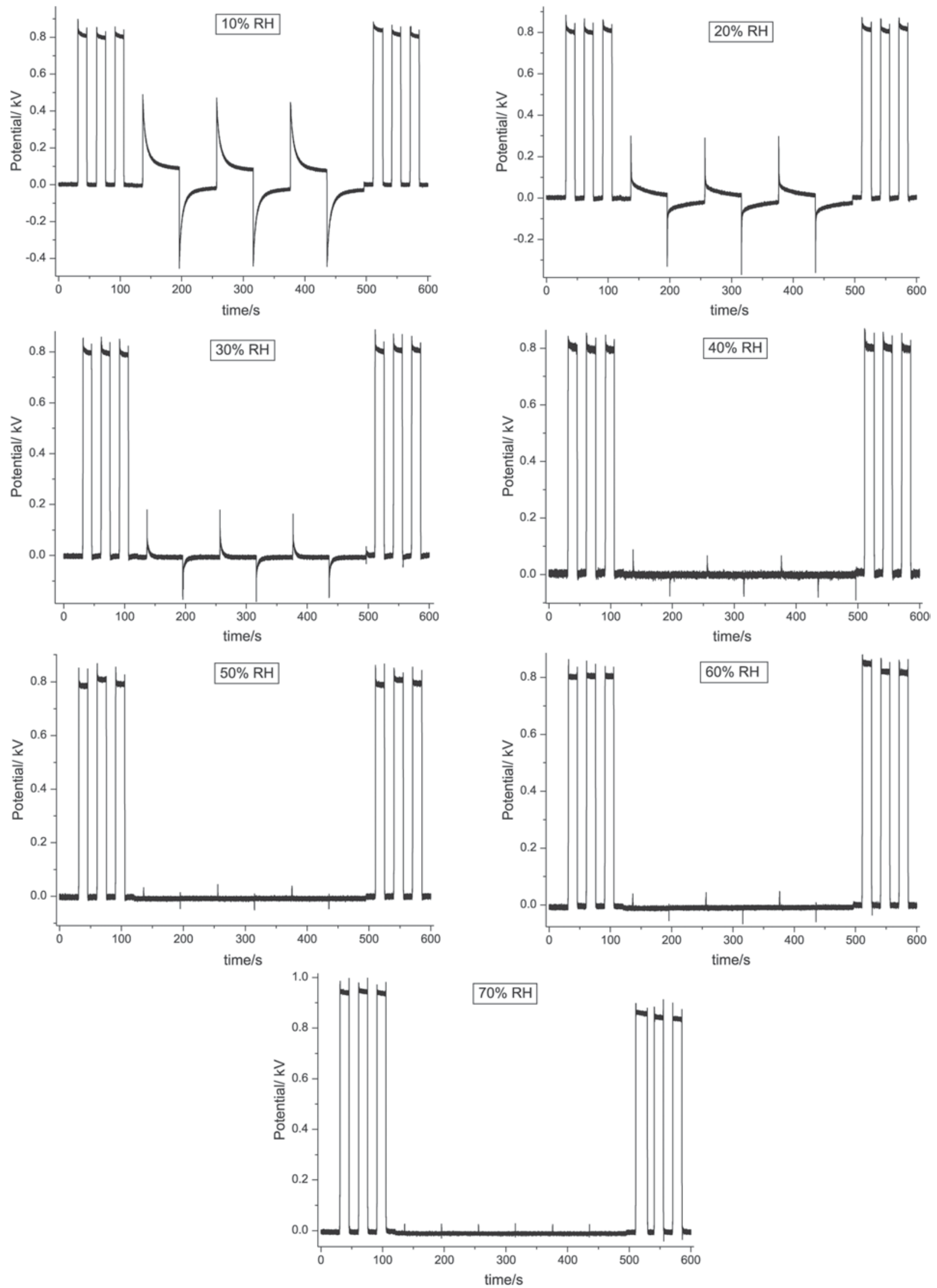

Figure 3. Potential vs. time curves recorded for paper sheet under nitrogen, 10-70\% relative humidity. 

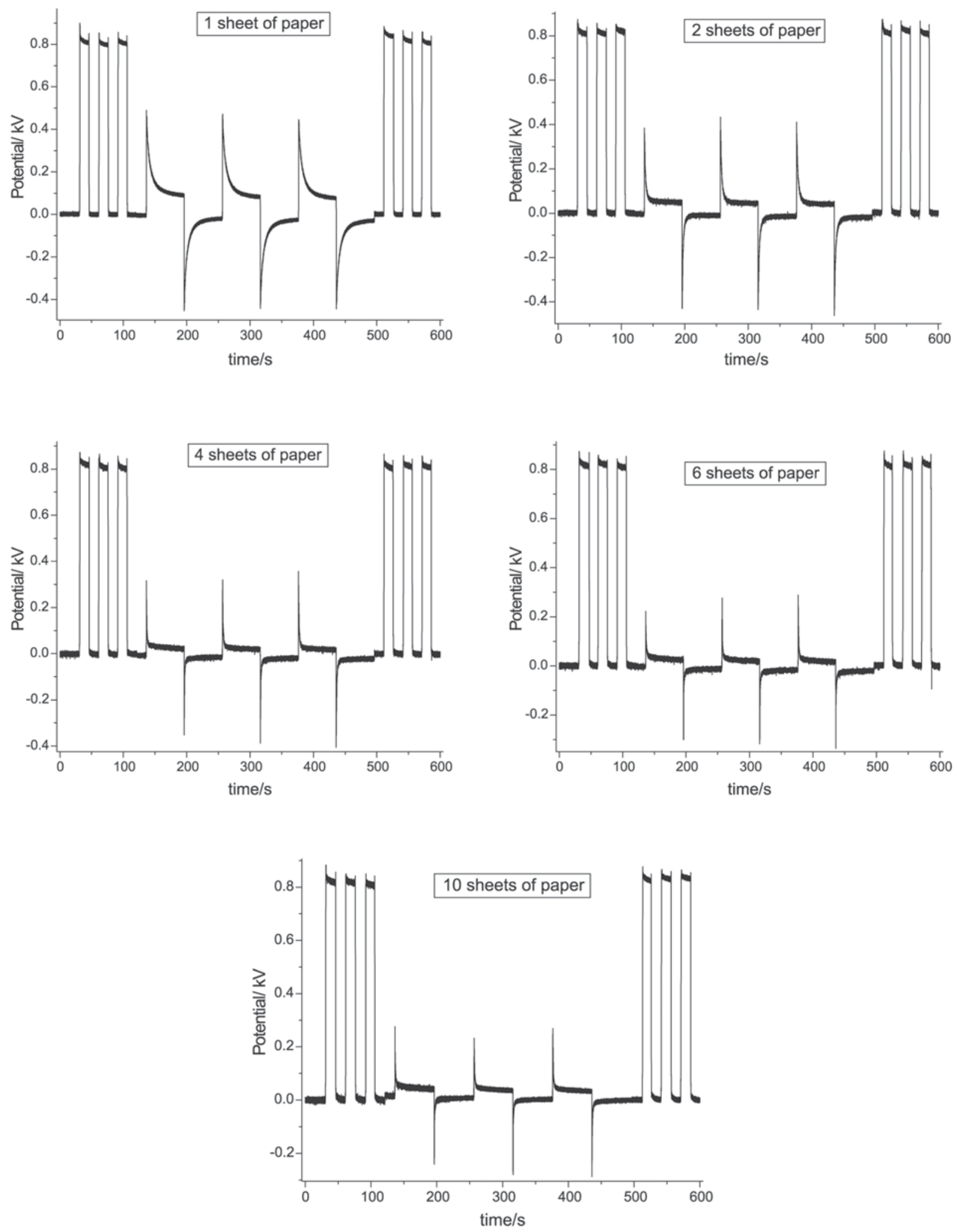

Figure 4. Potential vs. time curves recorded using different numbers of filter paper sheets, under $10 \% \mathrm{RH}$.

of this experiment are shown in Figure 6. They show that the introduction of the empty sample holder reduces the electric potential readings by 30 to $40 \%$, regardless of the relative humidity of the medium, and that this decrease is caused by the approximation of the grounded sample holder to the electrode. 


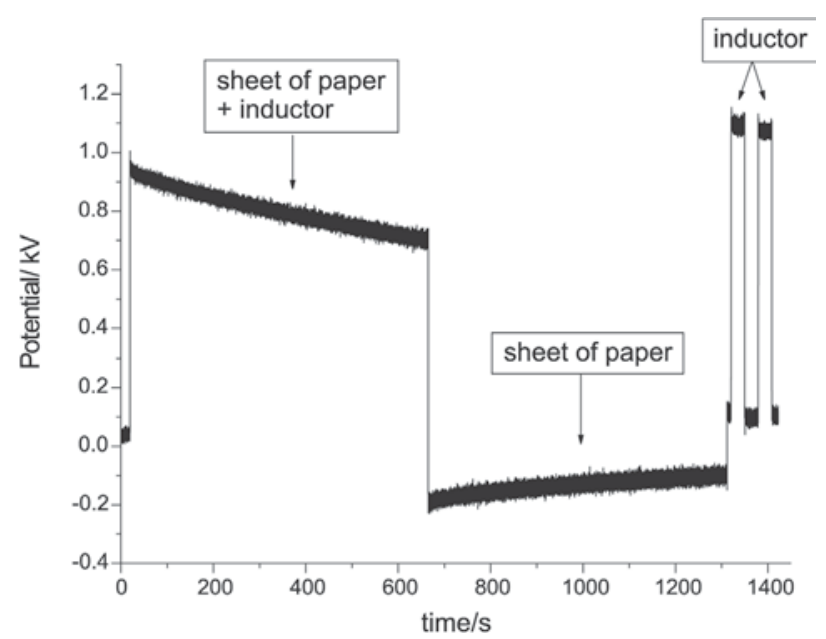

Figure 5. Potential $v s$. time curves recorded using only one filter paper sheet, in $0 \% \mathrm{RH}$.

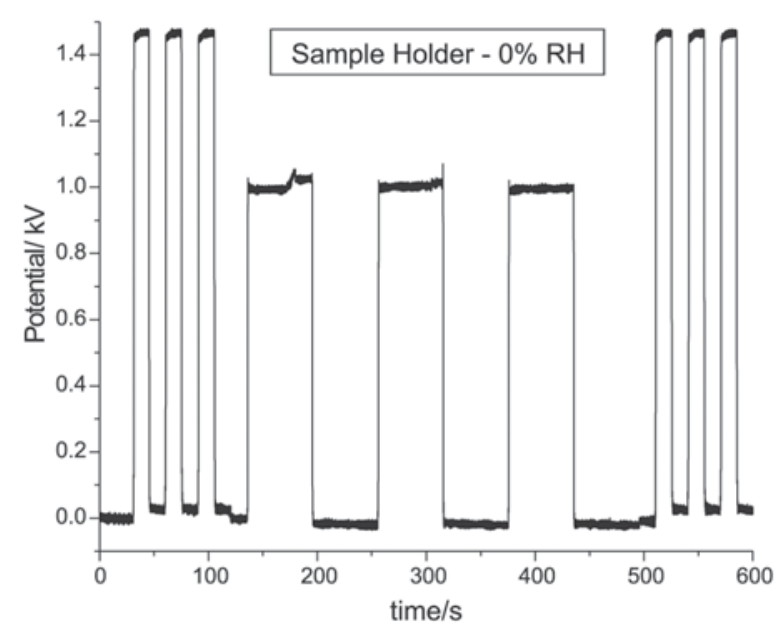

By using equation 2, we calculate that the paper dielectric constant contribution to the electric potential detected by the electrode is only $1 \%$.

Thus, for an experiment carried out at $10 \%$ RH, we can state that charges built-up on paper produce potentials as low as $500 \mathrm{~V}$ at the electrode probe. To have an estimate on the actual charge concentration required to create the potentials equation 3 was used. The calculated charge concentration is $1 \times 10^{-2}$ unit charge $/ \mu \mathrm{m}^{3}$.

\section{Discussion}

The results presented in this paper may be summed up as follows: i) Cellulose films acquire net excess charges opposite to the applied electrostatic potential in the presence of electrified bodies, under usual room temperature, pressure and relative humidity, as well as metals and semi-conductors

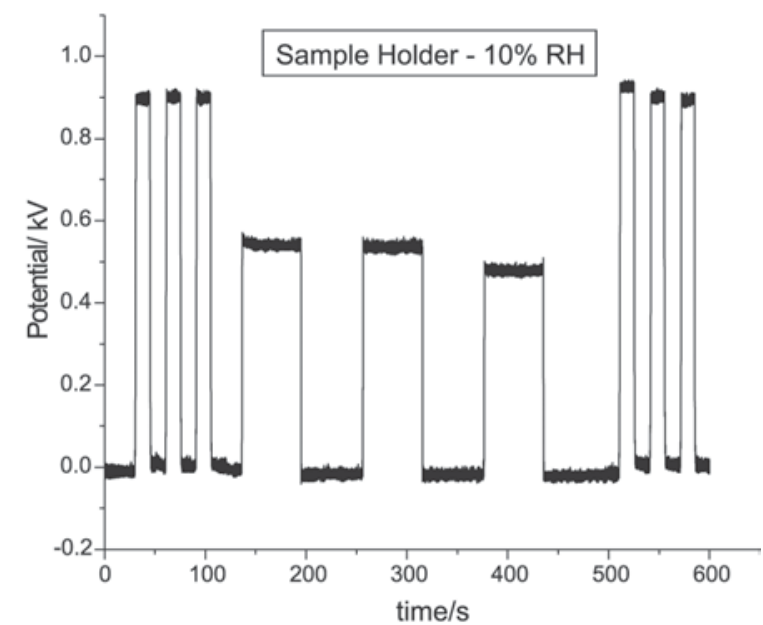

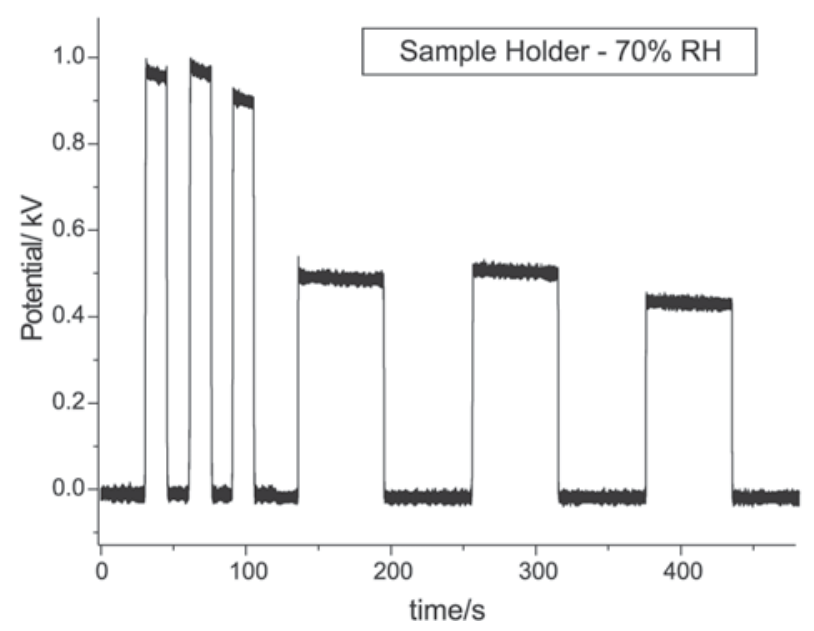

Figure 6. Potential vs. time curves recorded for the empty sample holder in 0,10 and $70 \% \mathrm{RH}$. 
can do. Paper can thus act as a shield between the electrode and an electrified inductor; ii) The rates of both the accumulation as well as the dissipation of the excess charges are faster under higher relative humidity of the surrounding atmosphere; iii) Creation and dissipation of charges follow symmetrical curves; $i v$ ) Charge creation and dissipation depends on the mass of water adsorbed on paper.

These results cannot be explained using the usual induction models that are adequate for metals or semiconductors, based on charge displacement across the insulator. On the other hand, they are consistent with the hypothesis that was put forward in the introduction of this paper, based on the sorption of atmospheric water on the insulator and the changes in the electrochemical potential and thus on the concentrations of $\mathrm{H}\left(\mathrm{H}_{2} \mathrm{O}\right)_{n}{ }^{+}$and $\mathrm{OH}\left(\mathrm{H}_{2} \mathrm{O}\right)_{n}{ }_{n}^{-}$ ions under a non-zero potential.

According to this model, just after the introduction of the electrified probe, there is the formation of a charged ionic atmosphere analogous to that formed within liquids but with a greater thickness (see Figure 7). In the water layer adsorbed on a solid surface there is also the accumulation of ions carrying excess charges opposite to the local potential. The excess ionic charge under an electrostatic potential $V$ is easily calculated using the equation for the chemical potential $\mu$ of the species $i$ carrying $z$ unit charges, under activity (concentration) $a,{ }^{20}$ given as equation 1. Thus, the introduction of a positive $V$ leads to a decrease in the activity $a$ (that is equal to concentration, since $\mathrm{H}^{+}$concentration is typically $10^{-5} \mathrm{~mol} \mathrm{~L}^{-1}$ ) of positive species, to reach equilibrium. The ratio between the concentration of negative and positive clusters under $500 \mathrm{~V}$ is $\ln \left(a_{-} / a_{+}\right)=2 \mathrm{eV} / \mathrm{RT}=2 \times 9.6 \times 10^{4} \times 500 /(8.3 \times 298)=4 \times 10^{4}$, meaning that under this potential the negative clusters largely predominate, at the surface. On the other hand, negative cluster accumulation is sufficiently large to actually decrease the potential measured by the electrode, according to Poisson-Boltzmann equation. ${ }^{21}$

The atmosphere that surrounds the insulator, sample and electrode changes and that is concurrent with a change in both $\mathrm{H}\left(\mathrm{H}_{2} \mathrm{O}\right)_{n}{ }^{+}$and $\mathrm{OH}\left(\mathrm{H}_{2} \mathrm{O}\right)_{n}{ }^{-}$ion concentration in the water layer adsorbed on the sample and other surfaces, as depicted in Figure 7. Charge density in the adsorption layer thus shields the measuring electrode from the poled inductor. Following this same argument, the electrostatic potential of the electrified plastic sheet used as an inductor is steady just because it has a low water adsorption capacity together with a low rate of water exchange with the atmosphere.

When the positive inductor is withdrawn leaving the samples in place, this bears a negative charge that is detected by the electrometer. The measured potentials fall back to zero within a short time, showing that the negative charges are quickly lost to the surrounding gas phase.

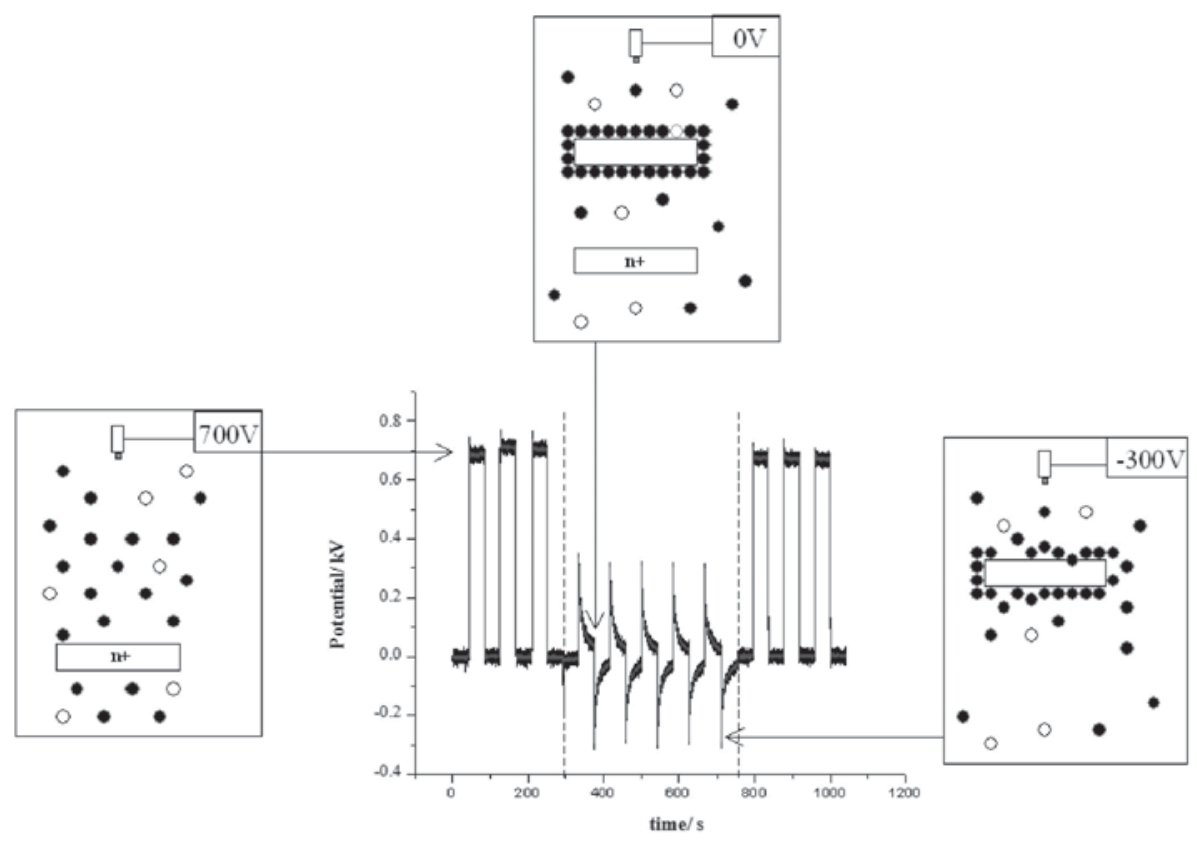

Figure 7. Schematic representation of the mechanism proposed for the observed potential changes. Left: the poled inductor is introduced beneath the electrode that reads the potential created by all charges in the vicinity, both in the inductor as well as in the atmosphere. Center: the sample is introduced between the poled inductor and the electrode. The accumulation of charged water cluster ions in the sample surface leads to a decrease in the potential read by the electrode. Right: the poled inductor is withdrawn and the voltmeter reads a potential generated by the excess negative charge at the sample surface. Black circles are negative ion clusters and the white circles are positive clusters. The potential vs. time plot in the center of the figure shows the points corresponding to the three states. 
Figures 3 and 4 show that the initial rate of shielding of the electrostatic potential generated by the inductor is very high and that the potential detected by the electrode decays exponentially with time. The variations in potential certainly have some correlation with the rate of charge build-up and distribution over the sample surfaces that will be further examined in future work.

The net accumulation of charged ions at surfaces and their exchange with the gas phase are not widespread ideas, but the existence of ionic aqueous clusters formed by hydration of ions generated by ionizing radiation and other processes in the atmosphere is experimentally wellestablished. ${ }^{22,23}$ In the open air, the population of ionic clusters is very complex, because the hydrated ion can bind atmospheric species such as $\mathrm{SO}_{2}$ and $\mathrm{CO}_{2}$ forming a variety of complex ions clusters in the gas phase. ${ }^{24}$ In the wet nitrogen atmosphere as well as in the adsorbed water layer the expected charged clusters are only $\left[\mathrm{H}\left(\mathrm{H}_{2} \mathrm{O}\right)_{\mathrm{n}}\right]^{+}$ and $\left[\mathrm{OH}\left(\mathrm{H}_{2} \mathrm{O}\right)_{\mathrm{n}}\right]^{-}$. Experimental evidence for charged water clusters on silica surface was presented by Turov and Myroniuk, based on ${ }^{1} \mathrm{H}$ NMR data. ${ }^{25}$

The proposed charge transfer to and from the insulator surface by water cluster ions is consistent with the strong symmetry of the potential $v s$. time curves observed in the presence of positive and negative (not shown) inductors. Symmetry of charge build-up and dissipation steps can be explained assuming that the charge-bearing species are similar, except for the charge sign, since they are all water clusters.

At $10 \% \mathrm{RH}, 2.61 \times 10^{-3} \mathrm{~atm}$ is the partial pressure of water in the atmosphere. ${ }^{19}$ The number of collisions between these molecules and the surface of paper a function of time, following the kinetic theory of gases, ${ }^{20}$ is approximately $10^{12}$ collisions per $\mu \mathrm{m}^{2}$ per second. The number of collisions between water molecules and the surface is considerably higher than the number of charges generated in the material $\left(1 \times 10^{-2}\right.$ unit charge/ $\left.\mu \mathrm{m}^{3}\right)$ showing that charge exchange with the atmosphere can account for charge build-up on the paper sheet.

Independent of any high-energy mechanism for ion

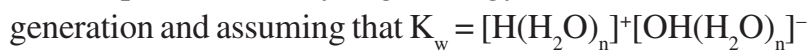
also holds for gas clusters, a fraction of atmospheric hydrous clusters as well as adsorbed water molecules, clusters or films should always carry charges, positive or negative, due to electric fields in which they are immersed. Moreover, these charges can be exchanged through the multiple reactions that characterize cluster dynamic equilibrium.

An excess concentration of positive water clusters is thus expected within a negative potential and vice-versa, both in the gas phase as well as in the adsorption layer. Provided the cluster size distribution is not strongly dependent on the charge sign, cluster adsorption/desorption rates should be similar in modulus, for the neutral, positive and negative clusters. Moreover, cluster mobility in the electric field should show the same modulus, irrespective of the charge signal. This explains why the potential variation curves are symmetrical and why they depend almost exclusively on the RH and on the number of sheets of paper.

The present model explains all of the experimental results reported in this paper and it is based on simple and classical concepts: the existence of ions in the atmosphere, water self-ionization equilibrium, formation of local excess charge density in a region of non-zero potential according to the Poisson-Boltzmann distribution, adsorption equilibrium. These concepts have been extensively applied in colloid and surface science but almost exclusively to the solid-liquid and liquid-liquid interfaces.

However, the interplay between electric potentials and adsorbed water has not been previously considered to explain charge induction in insulators even when the role of air humidity is well acknowledged ${ }^{26,27}$ to the best of the authors' knowledge. These arguments are relevant to understand the inadequacy of scanning tunneling microscopy in the study of water thin layers on solid surfaces. ${ }^{28} \mathrm{~A}$ very recent report assigns to adsorbed water and other atmospheric contaminants the disparity of polymer surface resistance measurements. ${ }^{29}$

Moreover, the present model also helps to understand the nature of "space charges" associated to dielectric absorption phenomena. These are often quoted but they are hardly identified with definite chemical species. We now propose that these are, in most dielectrics, just $\mathrm{H}\left(\mathrm{H}_{2} \mathrm{O}\right)_{n}{ }^{+}$ and $\mathrm{OH}\left(\mathrm{H}_{2} \mathrm{O}\right)_{\mathrm{n}}^{-}$ions formed and trapped within the solid.

Based on ideas analogous to those presented in this work, the connection between atmospheric electricity and electrostatic induction can be further developed but this will required a better knowledge on the nature and concentration of atmospheric ionic species than we have now ${ }^{30}$ and also on the state of water and other polar gases adsorbed on the surface of insulators.

The results presented in this paper are probably relevant to the interpretation of many intriguing phenomena described in this literature, for instance, the radiation-induced doping of polyanilines, when exposure to radiation significantly increases polyaniline condutivity. ${ }^{31-34}$ Mattoso et al. ${ }^{32}$ have shown that this only occurs in a moist atmosphere, for non-doped polyanilines.Other researchers have advanced the hypothesis that this increase in conductivity is partly due to ionization of water (caused by irradiation) adsorbed in these materials. ${ }^{33,34}$ Following the results presented, we can propose the following detailed mechanism: radiation 
produces fixed charges on the polymer due to heterolytic bond breakdown. This causes the accumulation of mobile positive or negative ions derived from water that account for increased polymer conductivity.

Moereover, these results can be used to explain charge distribution patterns that were observed in insulators, in the authors' laboratory, ${ }^{35-39}$ but have not yet been fully explained. This will be shown in a forthcoming publication.

\section{Conclusion}

Electrostatic induction on paper sheets under the approximation of an electrified body is consistent with a model based on water adsorption at the insulator surfaces and surface charging due to displacement of the water dissociation equilibrium under an electric potential, as expected from the properties of $\mathrm{H}_{(}\left(\mathrm{H}_{2} \mathrm{O}\right)_{n}{ }^{+}$and $\mathrm{OH}\left(\mathrm{H}_{2} \mathrm{O}\right)_{n}{ }^{-}$ electrochemical potentials.

\section{Acknowledgments}

LCS, TALB and SB acknowledge fellowships from CNPq and FAPESP. This is a contribution from the Millenium Institute for Complex Materials (IMMC)/ PADCT/CNPq.

\section{References}

1. Maxwell, J. C.; A Treatise on Electricity and Magnetism, Vol. 1, $3^{\text {rd }}$ ed., Dover: New York, 1892.

2. Schein, L. B.; Science 2007, 317, 43.

3. Bailey, A. G.; J. Electrostat. 2001, 51-52, 82.

4. Frenot, A.; Chronakis, I. S.; Curr. Opin. Colloid. In. 2003, 8, 64.

5. Castle, G. S. P.; Schein, L. B.; J. Electrostat. 1995, 36, 165.

6. Chen, G.; Tanaka, Y.; Takada, T.; Zhong, L.; IEEE T. Dielect. El. In. 2004, 11, 113.

7. Castle, G. S. P.; J. Electrostat. 1997, 40-41, 13.

8. Schein, L. B.; LaHa, M.; Marshall, G.; J. Appl. Phys. 1991, 69, 6817.

9. Jefimenko, O. D.; Walker, D. K.; Phys. Teach. 1980, December, 651.

10. Hogue, M. D.; Buhler, C. R.; Calle, C. I.; Matsuyama, T.; Luo, W.; Groop, E. E.; J. Electrostat. 2004, 61, 259.

11. Verdaguer, A.; Sacha, G. M.; Luna, M.; Ogletree, D. F.; Salmeron, M.; J. Chem. Phys. 2005, 123, 124703.

12. Folan, L. M.; Arnold, S.; O'Keeffe, T. R.; Spock, D. E.; Schein, L. B.; Diaz, A. F.; J. Electrostat. 1990, 25, 155.

13. Taillet, J.; Powder Technol. 2003, 135-136, 201.

14. Németh, E.; Albrecht, V.; Schubert, G.; Simon, F.; J. Electrostat. 2003, 58, 3 .
15. Yamamoto, T.; Tanioka, G.; Okubo, M.; Kuroki, T.; J. Electrostat. 2007, 65, 221.

16. Patton, S. T.; Cowan, W. D.; Eapen, K. C.; Zabinski, J. S.; Tribol. Lett. 2000, 9, 199.

17. Gouveia, R. F.; Costa, C. A. R.; Galembeck, F.; J. Phys. Chem. B 2005, 109, 4631.

18. Griffiths, D. J.; Introduction to Electrodynamics, $3^{\text {rd }}$ ed., Prentice Hall: Upper Saddle River, NJ, 1999.

19. Lide, D. R.; CRC Handbook of Chemistry and Physics, $84^{\text {th }}$ ed., CRC Press: Boca Raton, Florida, 2004.

20. Atkins, P. W.; Physical Chemistry, $6^{\text {th }}$ ed., Oxford University Press: Oxford, 1997.

21. Hunter, R. J.; Zeta Potential in Colloid Science, Academic Press: London, 1981.

22. Huertas, M. L.; Fontan, J.; Atmos. Environ. 1975, 9, 1018.

23. Sorokin, A.; Arnold, F.; Wiedner, D.; Atmos. Environ. 2005, 40, 2030.

24. Banic, C. M.; Iribarne, J. V.; J. Chem. Phys. 1985, 83, 6432.

25. Turov, V. V.; Mironyuk, I. F.; Colloid Surface A, 1998, 134, 257.

26. Engers, D. A.; Fricke, M. N.; Storey, R. P.; Newman, A. W.; Morris, K. R.; J. Electrostat. 2006, 64, 826.

27. Halima, F.; Barringer, S.A.; J. Electrostat. 2007, 65, 168.

28. Opitz, A.; Scherge, M.; Ahmed, S. I. U.; Schaefer, J. A.; J. Appl. Phys. 2007, 101, 064310.

29. Seaver, A. E.; J. Electrostat. 2005, 63, 203.

30. Vonnegut, B.; B. Am. Meteorol. Soc. 1994, 75, 53.

31. Shaw, M. A.; Kaplan, R. D.; Perreault, S.; J. Vac. Sci. Technol. B. 1989, 7, 1519 .

32. Malmonge, J. A.; Mattoso, L. H. C.; Synthetic Met. 1997, 84, 779.

33. Dhanabalan, A.; Malmonge, J. A.; Riul Jr., A.; Faria, R. M.; Oliveira Jr., O. N.; Thin Solid Films 1998, 327-329, 808.

34. Azevedo, W. M.; Lima, A. P. C.; Araujo, E. S.; Radiat. Prot. Dosim. 1999, 84, 77.

35. Galembeck, A.; Costa, C. A. R.; da Silva, M. C. V. M.; Souza, E. F.; Galembeck, F.; Polymer 2001, 42, 4845.

36. Keslarek, A. J.; Leite, C. A. P.; Galembeck, F.; J. Braz. Chem. Soc. 2004, 15, 66.

37. Galembeck, F.; Costa, C. A. R.; Galembeck, A.; Silva, M. D. C. V. M.; An. Acad. Bras. Cienc. 2001, 73, 495.

38. Costa, C. A. R.; Leite, C. A. P.; de Souza, E. F.; Galembeck, F.; Langmuir 2001, 17, 189.

39. Braga, M.; Costa, C. A. R.; Leite, C. A. P.; Galembeck, F.; J. Phys. Chem. B 2001, 105, 3005.

Received: August 30, 2007 Published on the web: February 22, 2008

FAPESP helped in meeting the publication costs of this article. 